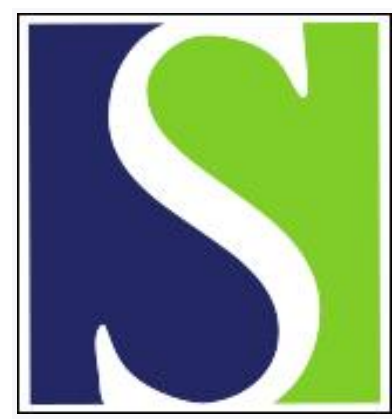

Scand J Work Environ Health 2008;34(4):288-296

https://doi.org/10.5271/sjweh.1267

Published online: 22 Sep 2008, Issue date: Aug 2008

Influence of job strain on changes in body mass index and waist circumference-6-year longitudinal study

by Ishizaki M, Nakagawa H, Morikawa Y, Honda R, Yamada Y, Kawakami N; The Japan Work Stress and Health Cohort Study Group

Affiliation: Social and Environmental Medicine, Kanazawa Medical University, 1-1 Daigaku, Uchinada, Ishikawa, Japan. hygiene@kanazawa-med.ac.jp

Refers to the following texts of the Journal: 1998;24(1):54-61 2004;30(2):85-128

The following articles refer to this text: 2013;39(3):241-258; 2017;43(6):587-594

Key terms: body mass index; change; job control; job demand; job strain; longitudinal study; waist circumference

This article in PubMed: www.ncbi.nlm.nih.gov/pubmed/18815715 


\title{
Influence of job strain on changes in body mass index and waist circumference-6-year longitudinal study
}

\author{
by Masao Ishizaki, PhD, ${ }^{1}$ Hideaki Nakagawa, PhD, ${ }^{2}$ Yuko Morikawa, PhD, ${ }^{2}$ Ryumon Honda, PhD, ${ }^{1}$ Yuichi \\ Yamada, PhD, ${ }^{1}$ Norito Kawakami, PhD, ${ }^{3}$ The Japan Work Stress and Health Cohort Study Group ${ }^{4}$
}

\begin{abstract}
Ishizaki M, Nakagawa H, Morikawa Y, Honda R, Yamada Y, Kawakami N, The Japan Work Stress and Health Cohort Study Group. Influence of job strain on changes in body mass index and waist circumference-6-year longitudinal study. Scand J Work Environ Health 2008;34(4):288-296.
\end{abstract}

\begin{abstract}
Objectives This study examined the effect of changes in psychosocial workplace characteristics on weight gain and abdominal obesity.

Methods Twice, at an interval of 6 years, the authors conducted examinations of job demand-control-support and measurements of body mass index and waist circumference among 2200 men and 1371 women aged 30-53 years and working in a factory. The scores of the psychosocial work characteristics in each examination were dichotomized at the median values for the men and women separately and then categorized into three groups as follows: group I: low score in both the first and second examinations, group II: low score in the first examination and high score in the second (or high at the first and low at the second), and group III: high in both the first and second examinations.

Results Although there was no statistically significant association between psychosocial work characteristics and the change in body mass index, for both genders, the change in waist circumference increased more in group III than in group I. Similarly, the odds ratios for the change in waist circumference above the 75th percentile for groups II and III increased more than in group I, being 1.13 [95\% confidence interval (95\% CI) $0.87-1.46$ and 1.39 (95\% CI 1.07-1.79) for the men in groups II and III, respectively, and 1.27 (95\% CI 0.90-1.78) and 1.78 (95\% CI 1.26-2.52) for the women in groups II and III, respectively.

Conclusions The results suggest that high job strain is a risk factor for increased abdominal obesity.
\end{abstract}

Key terms job control; job demand; waist circumference change.

Several studies have shown that psychosocial work stress, such as low job control and job strain combined with high job demand and low job control, which are considered to be work stressors in the job demand-control model proposed by Karasek, are related to the development of coronary heart disease (CHD) $(1,2)$. The pathophysiological mechanism underlying the relationship between work stress and CHD has been suggested to be increased ambulatory blood pressure $(3,4)$ and abnormalities of blood coagulation and fibrinolytic function (5).
On the other hand, although obesity is an important CHD risk factor, it is still unclear whether work stress is connected to weight gain. The metabolic syndrome, which is a pathophysiological state in which a cluster of factors such as abdominal obesity, atherogenic dyslipidemia, raised blood pressure, and glucose intolerance are believed to promote CHD, is attracting increasing attention (6). A cross-sectional analysis in the Whitehall II study suggested a biological explanation that socioeconomic inequality in CHD was partly attributable to the metabolic syndrome, because people with a lower

Social and Environmental Medicine, Kanazawa Medical University, Ishikawa, Japan.

Epidemiology and Public Health, Kanazawa Medical University, Ishikawa, Japan.

Department of Mental Health, University of Tokyo Graduate School of Medicine, Tokyo, Japan.

The Japan Work Stress and Health Cohort Study Group: T Haratani (National Institute of Industrial Health, Kawasaki, Japan), F Kobayashi (Aichi Medical University, Nagakute, Japan), S Araki (National Institute of Industrial Health, Kawasaki, Japan).

Reprint requests to: Dr M Ishizaki, Social and Environmental Medicine, Kanazawa Medical University, 1-1 Daigaku, Uchinada, Ishikawa, Japan. [E-mail: hygiene @kanazawa-med.ac.jp] 
socioeconomic status have a greater waist circumference (7). A recent Whitehall II study, with an average 14-year-follow-up, showed an association between chronic work stress and the metabolic syndrome, more exposure to a state of low support with job strain being associated with a greater risk of the metabolic syndrome even after adjustment for employment grade and health behavior (8).

Many epidemiologic investigations have used waist circumference or waist-to-hip ratio as an anthropometric measurement index of abdominal obesity, which is closely related to the metabolic syndrome. Rosmond et al (9) and Rosmond \& Björntorp (10) reported that inferior work conditions, such as less satisfaction with work management, less influence on work situations, and a lack of attempts to alter work situations, were associated with an increased waist-to-hip ratio.

In our previous cross-sectional investigation on Japanese employees, we found no statistically significant correlation between job demand-control and body mass index (BMI) or waist-to-hip ratio (11). However, we believe that a follow-up study would better clarify the influence of job demand-control on anthropometric measures, waist circumference, or waist-to-hip ratio, since, for example, considerable time must elapse before any changes in anthropometric measurements become apparent after exposure to certain work conditions. In addition, in the past decade, many companies in industrial countries have been trying to dynamically outrun others in the global economy race by introducing various managerial innovations, such as just-in-time production and total quality management (12). As a result, we can expect a rapid change in the work stress perceived by employees.

Therefore, in this study, we compared the results of two psychosocial work characteristics of the same persons in investigations conducted at an interval of 6 years and examined how changes in job demand-control affected the workers' anthropometric measurements.

\section{Study population and methods}

In our study, nonmanual and manual employees working for an aluminum-products factory in a rural area of Japan were asked to reply to the Japanese version of the job content questionnaire (13), about the status of job demand-control-support as individual psychosocial work characteristics. The survey was conducted twice, first from April 1996 through March 1997 and then from April 2002 through March 2003. On both occasions, only the persons who had provided their written consent to participate were included in the investigation. The selected workers were aged 30 to 53 years at the time of the first examination so that they were under 60 years of age, namely, the retirement age of the factory, at the time of the second examination. The participation rate of the first examination was $91.4 \%$ of the registered workers, or 2821 men and 1701 women, excluding pregnant women, as of 1 May 1996. Altogether 121 men and 39 women out of this population missed the opportunities or refused to consent to having their waist circumference measured. Before the second examination, 186 men and 184 women had resigned and 185 men had been transferred, and consequently they were excluded from the follow-up. Furthermore, 72 men and 97 women who did not reply to the second job content questionnaire or failed to undergo the second waist circumference measurement were also excluded.

Altogether, we included 2200 men and 1371 women as eligible participants whose data from the questionnaire and anthropometric measurements at both examinations were available and who had given complete replies to the questions concerning the confounding factors, such as sedentary job, shift work, and other health behavior, at the first examination. Managers and professionals accounted for $14 \%$ of all the men, whereas only $2 \%$ of the women were managers or professionals.

Job strain was calculated as a value of job demand divided by job control. The median value of each psychosocial work characteristic of the participants from the age of 30 to 53 years did not change between the two surveys. The median values of the job demand scores, the job control scores, and the scores for worksite support were 66, 32 and 23 for the men and 60, 32, and 22 for the women, respectively. But the median values of the job strain scores slightly changed, from 0.485 for the men and 0.533 for the women in the first examination to 0.500 for the men and 0.536 for the women, respectively, in the second examination. The scores for job control, job demand, worksite support, and job strain in each examination were dichotomized at the median value for the men and women separately and then categorized into three groups as follows: group I: low score in both the first and second examinations, group II: low score in the first examination and high score in the second (or high in the first and low in the second), and group III: high in both the first and second examinations (figure 1).

\section{Anthropometric measurements}

Anthropometric measurements were conducted within a month before or after the questionnaire survey on both occasions, the weight, height, and waist circumference of the participants being measured with them wearing light clothes. The BMI $\left(\mathrm{kg} / \mathrm{m}^{2}\right)$ of the participants was calculated by dividing their weight by their height squared. The waist circumference (centimeters) was 


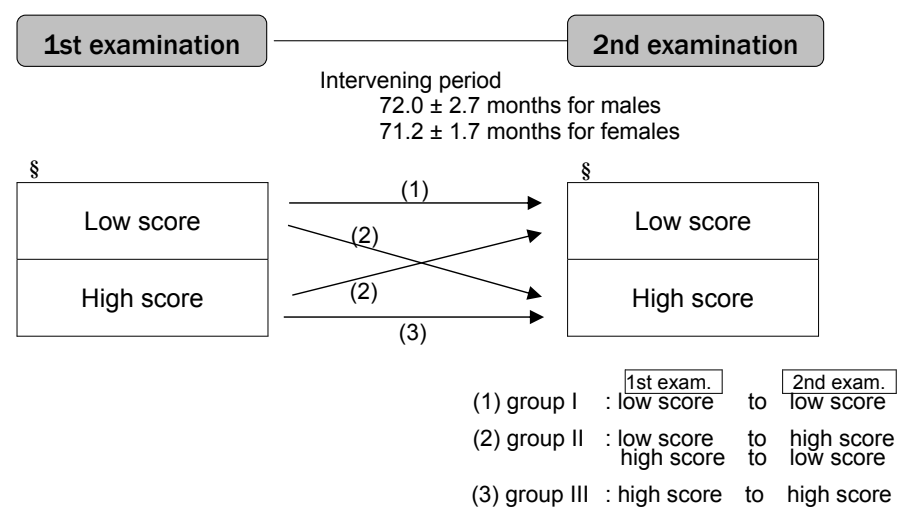

Figure 1. Categorization according to the change in psychosocial work characteristics. $[\S=$ The scores for job control, job demands, worksite support, and job strain (demand and control) in each examination were dichotomized at the median value for 2200 men and 1371 women after those with no job content questionaire or anthropometric measurement data on either occation were excluded or who resigned or transferred after the 1st examination.]

measured at the umbilicus level by experienced nurses. Underwear worn to correct body shape was removed.

\section{Sedentary job and shift work as other work character- istics}

Sedentary job was categorized into three groups according to the average number of sedentary hours per workday in the previous year (" $<1$ hour", " $\geq 1$ and $\leq 4$ hours", and " $\geq 5$ hours"). The three-shift workers who worked nights were categorized as a shift work group, as opposed to a nonshift work group. No female worker in the factory was engaged in three-shift work.

\section{Other health behavior}

Queries were made about several lifestyle factors. The workers were classified as "non- or ex-smokers" and "current smokers". Alcohol consumption was measured in terms of grams of ethanol consumed per week and was categorized into five groups for the men (ie, no drinking, 1-175 g/week, 176-350 g/week, 351-525 g/week, and $\geq 526 \mathrm{~g} /$ week). As only five women ingested more than 350 grams of alcohol per week, alcohol consumption was re-categorized into three groups as follows: nondrinker, $1-175 \mathrm{~g} /$ week, and $\geq 175 \mathrm{~g} /$ week. Exercise for the men was classified as "almost no exercise", "light exercise", "brisk and sweating exercise once or twice a week" and "brisk and sweating exercise more than three times a week". The degree of education for the men was determined by the total years of education and was classified as " $<11$ years", "11-12 years", "13-14 years", and " $\geq 15$ years" of education. Since relatively few women participated in brisk and sweating exercise more than three times a week or had more than 15 years of education, exercise and education were re-categorized into three groups for the women ("almost no exercise", "light exercise", and "brisk and sweating exercise" and " $<11$ years", "11-12 years", and " $\geq 13$ years", respectively). Marital status was divided into "married" and "previously or never married".
This study was approved by the Ethics Committee of the Kanazawa Medical University.

\section{Statistical analyses}

The data were analyzed separately for the men and women using an SAS program package (SAS Inc, Cary, NC, USA). Changes in BMI and waist circumference were expressed as (second examination value - first examination value) / first examination value. The BMI and waist circumference in the first examination, the change in BMI, and the change in waist circumference were compared among different groups using a general linear model. The data for sedentary job, shift work, smoking habits, alcohol consumption, exercise, education, and marital status (inquired about in the first examination) were adopted as potential confounding factors.

Logistic regression analyses were used to calculate the odds ratios of the change in BMI and the change in waist circumference above the 75th percentile according to changing job strain; they were 0.0458 and 0.0600 for the men and 0.0456 and 0.1080 for the women, respectively.

\section{Results}

The mean period from the first to the second examination of the job content questionnaire was 72.0 (SD 2.7) months for the men and 71.2 (SD 1.7) months for the women.

Table 1 shows the differences in the mean values for age, BMI, waist circumference, and psychosocial work characteristics in the first examination between the workers with complete data from the two surveys and those for whom only data from the first examination were available. For the men, those who participated in both examinations were younger and had lower job control than those who participated only in the first examination. For the women, the latter group was younger and had 
Table 1. Mean levels and standard deviations (SD) of the body mass index (BMI), waist circumference, and psychosocial work characteristics at the first examination for those who participated in both the baseline and the follow-up examinations and those who participated only at the baseline.

\begin{tabular}{|c|c|c|c|c|c|c|c|c|c|c|c|c|c|c|}
\hline & \multicolumn{7}{|c|}{ Men } & \multicolumn{7}{|c|}{ Women } \\
\hline & \multirow[t]{2}{*}{$\mathrm{N}$} & \multicolumn{2}{|c|}{$\begin{array}{l}\text { Particpation } \\
\text { at baseline } \\
\text { and in follow-up }\end{array}$} & \multirow[t]{2}{*}{$N$} & \multicolumn{2}{|c|}{$\begin{array}{l}\text { Participation } \\
\text { at baseline } \\
\text { only }\end{array}$} & \multirow[t]{2}{*}{ P-value } & \multirow[t]{2}{*}{$\mathrm{N}$} & \multicolumn{2}{|c|}{$\begin{array}{l}\text { Particpation } \\
\text { at baseline } \\
\text { and in follow-up }\end{array}$} & \multirow[t]{2}{*}{$\mathrm{N}$} & \multicolumn{2}{|c|}{$\begin{array}{l}\text { Participation } \\
\text { at baseline } \\
\text { only }\end{array}$} & \multirow[t]{2}{*}{$P$-value } \\
\hline & & Mean & SD & & Mean & SD & & & Mean & SD & & Mean & SD & \\
\hline Age & 2200 & 41.8 & 6.4 & 778 & 42.7 & 6.8 & $<0.01$ & 1371 & 41.7 & 6.3 & 378 & 43.9 & 7.7 & $<0.01$ \\
\hline $\mathrm{BMI}\left(\mathrm{kg} / \mathrm{m}^{2}\right)$ & & 23.2 & 2.8 & 778 & 23.3 & 2.8 & 0.42 & & 22.4 & 3.2 & 378 & 22.6 & 3.4 & 0.24 \\
\hline Waist (cm) & & 79.6 & 7.7 & 657 & 80.2 & 7.4 & 0.09 & & 71.7 & 8.7 & 328 & 73.3 & 9.9 & $<0.01$ \\
\hline Job control & & 65.2 & 10.0 & 751 & 66.3 & 10.4 & 0.02 & & 58.6 & 10.0 & 348 & 58.1 & 10.4 & 0.35 \\
\hline Job demand & & 32.0 & 4.8 & 761 & 32.0 & 4.7 & 0.82 & & 31.6 & 5.0 & 357 & 31.7 & 5.0 & 0.81 \\
\hline Worksite support & & 21.8 & 3.2 & 748 & 21.8 & 3.1 & 0.78 & & 21.3 & 3.3 & 370 & 21.2 & 3.8 & 0.74 \\
\hline Job strain & & 0.504 & 0.118 & 740 & 0.495 & 0.119 & 0.06 & & 0.557 & 0.141 & 329 & 0.567 & 0.174 & 0.33 \\
\hline
\end{tabular}

Table 2. Body mass index (BMI) and waist circumference in the first examination according to the change in the psychosocial work characteristics. (group I = low score in both the first and second examinations, group II = low score in first examination and high score in second examination or high score in first examination but low score in second examination, group III = high score in both the first and second examinations)

\begin{tabular}{|c|c|c|c|c|c|c|c|c|c|c|}
\hline & \multicolumn{5}{|c|}{ Men } & \multicolumn{5}{|c|}{ Women } \\
\hline & \multirow[t]{2}{*}{$\mathrm{N}$} & \multicolumn{2}{|c|}{$\mathrm{BMI}\left(\mathrm{kg} / \mathrm{m}^{2}\right)$} & \multicolumn{2}{|c|}{ Waist (cm) } & \multirow[t]{2}{*}{$\mathrm{N}$} & \multicolumn{2}{|c|}{$\mathrm{BMI}\left(\mathrm{kg} / \mathrm{m}^{2}\right)$} & \multicolumn{2}{|c|}{ Waist (cm) } \\
\hline & & Unadjusted & Adjusted $^{a}$ & Unadjusted & Adjusted $^{\mathrm{b}}$ & & Unadjusted & Adjusted a & Unadjusted & Adjusted \\
\hline \multicolumn{11}{|l|}{ Job control } \\
\hline Group I & 863 & 23.0 & 23.5 & 79.1 & 80.6 & 569 & 22.4 & 23.2 & 71.7 & 72.0 \\
\hline Group II & 635 & 23.1 & 23.6 & 79.1 & 80.4 & 442 & 22.4 & 23.1 & 71.5 & 71.8 \\
\hline Group III & 702 & 23.5 & 23.8 & 80.8 & 81.5 & 360 & 22.4 & 23.3 & 72.2 & 72.4 \\
\hline P-value & & $<0.01$ & 0.17 & $<0.01$ & 0.05 & & 0.98 & 0.86 & 0.50 & 0.62 \\
\hline \multicolumn{11}{|l|}{ Job demand } \\
\hline Group I & 591 & 23.3 & 23.8 & 80.3 & 81.6 & 371 & 22.3 & 23.1 & 72.1 & 72.6 \\
\hline Group II & 731 & 23.0 & 23.5 & 78.8 & 80.2 & 509 & 22.4 & 23.2 & 71.1 & 71.6 \\
\hline Group III & 878 & 23.3 & 23.8 & 79.9 & 81.1 & 491 & 22.5 & 23.2 & 72.1 & 72.5 \\
\hline P-value & & 0.03 & 0.04 & $<0.01$ & $<0.01$ & & 0.66 & 0.89 & 0.12 & 0.17 \\
\hline \multicolumn{11}{|c|}{ Worksite support } \\
\hline Group I & 615 & 23.3 & 23.8 & 79.5 & 81.0 & 496 & 22.5 & 23.3 & 71.9 & 72.0 \\
\hline Group II & 802 & 23.2 & 23.6 & 79.6 & 80.9 & 510 & 22.5 & 23.2 & 71.7 & 71.8 \\
\hline Group III & 783 & 23.2 & 23.6 & 79.7 & 80.9 & 365 & 22.1 & 22.9 & 71.6 & 71.7 \\
\hline P-value & & 0.60 & 0.39 & 0.91 & 0.90 & & 0.14 & 0.20 & 0.88 & 0.86 \\
\hline \multicolumn{11}{|l|}{ Job strain } \\
\hline Group I & 619 & 23.4 & 23.8 & 80.5 & 81.5 & 358 & 22.3 & 23.1 & 72.3 & 72.6 \\
\hline Group II & 801 & 23.1 & 23.6 & 79.4 & 80.6 & 554 & 22.6 & 23.3 & 71.7 & 72.0 \\
\hline Group III & 780 & 23.1 & 23.7 & 79.2 & 80.7 & 459 & 22.4 & 23.1 & 71.4 & 71.8 \\
\hline P-value & & 0.22 & 0.46 & $<0.01$ & 0.07 & & 0.36 & 0.58 & 0.35 & 0.46 \\
\hline
\end{tabular}

a Adjusted for age, sedentary job, shift work (only men), smoking, alcohol, exercise, education, and marital status in model 1.

${ }^{\mathrm{b}}$ Adjusted for the factors listed for model 1 and also BMI in the first examination.

slenderer waists. The mean scores for job control, job demand, and worksite support among the workers who participated in both examinations were 65.2 (SD 10.0), 32.0 (SD 4.8), and 21.8 (SD 3.2), respectively, for the men and 58.6 (SD 10.0), 31.6 (SD 5.0), and 21.3 (SD $3.3)$, respectively, for the women. These scores did not differ very much from the scores of other large population studies of Japanese (14) and Belgians (15).

Regarding the association between psychosocial work characteristics and lifestyle at the first examination, there were no differences in smoking habits or alcohol consumption between the low and high psychosocial 
Table 3. Change in body mass index (BMI) and waist circumference according to changes in job control, job demand, and worksite support. (group I = low score in both the first and second examinations, group $\mathrm{II}=$ low score in first examination and high score in second examination or high score in first examination but low score in second examination, group III = high score in both the first and second examinations)

\begin{tabular}{|c|c|c|c|c|}
\hline & \multicolumn{2}{|r|}{ Men } & \multicolumn{2}{|c|}{ Women } \\
\hline & $\begin{array}{c}\text { Change in } \\
\mathrm{BMI}^{\mathrm{a}}\end{array}$ & $\begin{array}{l}\text { Change in waist } \\
\text { circumference }^{b}\end{array}$ & $\begin{array}{c}\text { Change in } \\
\mathrm{BMI}^{\mathrm{a}}\end{array}$ & $\begin{array}{l}\text { Change in waist } \\
\text { circumference }^{b}\end{array}$ \\
\hline \multicolumn{5}{|l|}{ Job control } \\
\hline Group I & 0.009 & 0.018 & 0.021 & 0.061 \\
\hline Group II & 0.013 & 0.022 & 0.020 & 0.057 \\
\hline Group III & 0.011 & 0.016 & 0.017 & 0.050 \\
\hline P-value & 0.36 & 0.16 & 0.56 & 0.32 \\
\hline \multicolumn{5}{|l|}{ Job demand } \\
\hline Group I & 0.009 & 0.016 & 0.019 & 0.049 \\
\hline Group II & 0.010 & 0.017 & 0.018 & 0.057 \\
\hline Group III & 0.012 & 0.021 & 0.019 & 0.055 \\
\hline P-value & 0.39 & 0.18 & 0.92 & 0.50 \\
\hline \multicolumn{5}{|c|}{ Worksite support } \\
\hline Group I & 0.012 & 0.018 & 0.017 & 0.056 \\
\hline Group II & 0.012 & 0.019 & 0.021 & 0.061 \\
\hline Group III & 0.009 & 0.017 & 0.019 & 0.049 \\
\hline P-value & 0.48 & 0.84 & 0.65 & 0.21 \\
\hline
\end{tabular}

${ }^{a}$ Adjusted for age, sedentary job, shift work (only men), smoking, alcohol, exercise, education, and marital status in model 1.

${ }^{b}$ Adjusted for the factors listed for model 1 and also for BMI in the first examination.

work characteristic groups of either gender. More men in the high job-strain group had standing work, shift work, no regular exercise, and shorter education and were not married in comparison with the men in the low job-strain group. The women in the high job-strain group had more standing work, less regular exercise, and shorter education than those in the low job-strain group. The men in the low worksite-support group had more standing work and shorter education than those in the high worksitesupport group. No difference between the low and the high worksite-support groups was found for the women (data not shown).

Table 2 on page 291 shows the mean BMI levels and waist circumference values according to the subgroups of job control, job demand, worksite support, and job strain in the first examination. For the men, both the BMI and waist circumference were larger in group III than in group I for job control and similarly larger in group I and III than in group II for job demand. As regards job strain, group I had the largest waist circumference among the three groups. For the women, there were no statistically significant differences in BMI or waist circumference among the subgroups of any of the psychosocial work characteristics. After adjustment for potential confounding factors, these differences did not change much for either gender.
The associations of the change in BMI and the change in waist circumference (after adjustment for the confounding factors) with job control, job demand, worksite support, and job strain are shown in table 3 and table 4. No significant difference was found in the change in BMI among the three different groups of the psychosocial work characteristics for either gender. The change in waist circumference was significantly higher in group III for job strain than in groups I and II among the men, and also a marginally significant similarity was found for the women. There was no significant interaction between job strain and the other work conditions (ie, sedentary work and shift work) with respect to the values of the change in BMI or the change in waist circumference. In the analyses of the relationship between job strain and the change in BMI and the change in waist circumference, BMI was categorized into slender, moderate, and overweight groups. Hereupon the moderate group denoted the mean value plus or minus one standard deviation of the BMI in the first examination. The ranges of the slender, moderate, and overweight groups were $<20.38 \mathrm{~kg} / \mathrm{m}^{2}, 20.38-26.02 \mathrm{~kg} / \mathrm{m}^{2}$, and $\geq 26.03 \mathrm{~kg} / \mathrm{m}^{2}$ for the men and $<19.18 \mathrm{~kg} / \mathrm{m}^{2}, 19.18-25.66 \mathrm{~kg} / \mathrm{m}^{2}$, and $\geq 25.67 \mathrm{~kg} / \mathrm{m}^{2}$ for the women, respectively. For the men, the proportions of people in the overweight group at the first examination who gained weight or had an increase in their waist circumference during the period between the two examinations were $53.1 \%$ (BMI) and $59.3 \%$ (waist). The rates were lower than those in the slender and moderate groups at the first examination. The change in BMI in the overweight group at the first examination was also smaller than that in the slender or moderate group for both genders.

On the other hand, the change in waist circumference increased in all of the BMI categories of slender, moderate, and overweight at the first examination. The change in waist circumference among the men was larger in group III than that in group I or group II. The change in waist circumference in group III was similarly larger than that in group I or group II for both the moderate and overweight women in the first examination.

For those who lost weight during the interval between the first and second examinations, no significant difference in the change in BMI or the change in waist circumference was found among the three job-strain groups (data not shown).

Table 5 shows the odds ratios of the change in BMI and the change in waist circumference above the 75th percentile according to the changes in job strain. Regarding the change in waist circumference for both genders, group III showed a significantly higher rate of change than group I. The odds ratios were 1.13 [95\% confidence interval (95\% CI) $0.87-1.46$ ] in group II and 1.39 (95\% CI 1.07-1.79) in group III for the men and 1.27 (95\% 
Table 4. Change in body mass index (BMI) and waist circumference in relation to job strain according to the BMI category in the first examination. (job-strain group I = low score in both the first and second examinations, job-strain group II = low score in first examination and high score in second examination or high score in first examination but low score in second examination, job-strain group III = high score in both the first and second examinations)

\begin{tabular}{|c|c|c|c|c|c|c|c|c|c|c|}
\hline \multirow[t]{2}{*}{ BMI in the first examination } & \multicolumn{5}{|c|}{ Change in BMI } & \multicolumn{5}{|c|}{ Change in waist circumference } \\
\hline & $\begin{array}{l}\text { Persons with } \\
\text { weight gain } \\
(\%)\end{array}$ & $\begin{array}{l}\text { Job- } \\
\text { strain } \\
\text { group I }\end{array}$ & $\begin{array}{l}\text { Job- } \\
\text { strain } \\
\text { group II }\end{array}$ & $\begin{array}{l}\text { Job- } \\
\text { strain } \\
\text { group III }\end{array}$ & $\begin{array}{c}\mathrm{P}- \\
\text { value }\end{array}$ & $\begin{array}{c}\text { Persons with } \\
\text { waist increase } \\
(\%)\end{array}$ & $\begin{array}{l}\text { Job- } \\
\text { strain } \\
\text { group I }\end{array}$ & $\begin{array}{l}\text { Job- } \\
\text { strain } \\
\text { group II }\end{array}$ & $\begin{array}{l}\text { Job- } \\
\text { strain } \\
\text { group III }\end{array}$ & $\begin{array}{c}\mathrm{P}- \\
\text { value }\end{array}$ \\
\hline \multicolumn{11}{|l|}{ Slendera } \\
\hline $\begin{array}{l}\text { Men }\left(<20.38 \mathrm{~kg} / \mathrm{m}^{2}\right) \\
(\mathrm{N}=345)^{\mathrm{b}} \\
\text { Women }\left(<19.18 \mathrm{~kg} / \mathrm{m}^{2}\right)\end{array}$ & $65.2^{\mathrm{c}}$ & 0.011 & 0.016 & 0.020 & . & $65.5^{\mathrm{c}}$ & 0.023 & 0.009 & 0.015 & . \\
\hline$(\mathrm{N}=170)^{\mathrm{b}}$ & $62.9^{c}$ & 0.012 & 0.019 & 0.022 & . & $60.6^{c}$ & 0.040 & 0.064 & 0.059 & . \\
\hline \multicolumn{11}{|l|}{ Moderate ${ }^{a}$} \\
\hline $\begin{array}{l}\operatorname{Men}\left(20.38-26.02 \mathrm{~kg} / \mathrm{m}^{2}\right) \\
(\mathrm{N}=1523)^{\mathrm{b}}\end{array}$ & $62.4^{c}$ & 0.012 & 0.016 & 0.015 & . & $66.6^{c}$ & 0.031 & 0.033 & 0.032 & . \\
\hline $\begin{array}{l}\text { Women }\left(19.18-25.66 \mathrm{~kg} / \mathrm{m}^{2}\right) \\
(\mathrm{N}=1003)^{\mathrm{b}}\end{array}$ & $63.5^{c}$ & 0.016 & 0.023 & 0.025 & . & $66.1^{\mathrm{c}}$ & 0.021 & 0.030 & 0.042 & . \\
\hline \multicolumn{11}{|l|}{ Overweight a } \\
\hline Men $\left(\geq 26.03 \mathrm{~kg} / \mathrm{m}^{2}\right)(\mathrm{N}=332)^{\mathrm{b}}$ & $53.1^{c}$ & -0.008 & -0.009 & 0.008 & . & $59.3^{c}$ & -0.005 & 0.002 & 0.007 & . \\
\hline Women $\left(\geq 25.67 \mathrm{~kg} / \mathrm{m}^{2}\right)(\mathrm{N}=198)^{\mathrm{b}}$ & $60.6^{c}$ & 0.013 & 0.012 & 0.022 & . & $65.7^{\mathrm{c}}$ & 0.073 & 0.074 & 0.084 & . \\
\hline \multicolumn{11}{|l|}{ Total } \\
\hline Men & . & $0.008^{d}$ & 0.010 & 0.013 & 0.26 & . & $0.013^{e}$ & 0.019 & 0.022 & 0.03 \\
\hline Women & . & $0.018^{d}$ & 0.019 & 0.020 & 0.89 & . & $0.046^{e}$ & 0.055 & 0.065 & 0.04 \\
\hline
\end{tabular}

a BMI category: slender $=<($ mean-SD $)$, moderate $=($ mean $-S D)-($ mean $+S D)$, overweight $=\geq($ mean $+S D)$.

${ }^{b}$ Number of persons in each BMI category.

c Percentage of persons in each BMI category with weight gain or waist increase during the period.

d Adjusted for age, sedentary job, shift work (only men), smoking, alcohol, exercise, education, and marital status in model 1.

${ }^{\text {e }}$ Adjusted for the factors listed for model 1 and also BMI in the first examination.

Table 5. Odds ratios (OR) and their $95 \%$ confidence intervals $(95 \% \mathrm{Cl})$ for the change in body mass index (BMI) and waist circumference above the 75th percentile according to job-strain change. (group I = low score in both the first and second examinations, group II = low score in first examination and high score in second examination or high score in first examination but low score in second examination, group III = high score in both the first and second examinations)

\begin{tabular}{|c|c|c|c|c|c|c|c|c|}
\hline \multirow[t]{3}{*}{ Job strain } & \multicolumn{4}{|c|}{ Change in $\mathrm{BMI}{ }^{\mathrm{a}}$} & \multicolumn{4}{|c|}{ Change in waist circumference ${ }^{b}$} \\
\hline & \multicolumn{2}{|c|}{ Men } & \multicolumn{2}{|c|}{ Women } & \multicolumn{2}{|c|}{ Men } & \multicolumn{2}{|c|}{ Women } \\
\hline & $\mathrm{OR}$ & $95 \% \mathrm{Cl}$ & OR & $95 \% \mathrm{Cl}$ & $\mathrm{OR}$ & $95 \% \mathrm{Cl}$ & $\mathrm{OR}$ & $95 \% \mathrm{Cl}$ \\
\hline Group I & 1 & $\cdot$ & 1 & . & 1 & . & 1 & . \\
\hline Group II & 1.05 & $0.82-1.35$ & 1.05 & $0.77-1.44$ & 1.13 & $0.87-1.46$ & 1.27 & $0.90-1.78$ \\
\hline Group III & 1.23 & $0.95-1.59$ & 0.92 & $0.66-1.29$ & 1.39 & $1.07-1.79$ & 1.78 & $1.26-2.52$ \\
\hline
\end{tabular}

${ }^{a}$ Adjusted for age, sedentary job, shift work (only men), smoking, alcohol, exercise, education, and marital status in model 1.

${ }^{\mathrm{b}}$ Adjusted for the factors listed for model 1 and also for BMI in the first examination.

CI 0.90-1.78) in group II and 1.78 (95\% CI 1.26-2.52) in group III for the women.

\section{Discussion}

This 6-year follow-up study showed that the change in waist circumference in job-strain group III increased more than that in job-strain group I, even though no statistically significant association was noted between the psychosocial work characteristics and the change in BMI. Moreover, the prevalence rate of the change in waist circumference above the 75th percentile among both the men and women increased progressively in order from group I to group II to group III of job strain after adjustment for age, BMI, sedentary job, shift work, smoking, alcohol, exercise, education, and marital status. The results of this study showed that high job strain may contribute to abdominal obesity.

Although two previous cross-sectional investigations referred to the association between job strain and abdominal obesity among men $(16,17)$, one review noted that the association was not clear (18). Recently, 
Brunner et al (19) showed that job strain partly caused abdominal obesity, because a dose-response relationship between work stress and obesity was found in their 19year follow-up study. With an increased number of cases classified as iso-strain (ie, the lowest tertile of worksite support combined with job strain, evaluated on four occasions during the follow-up), the incidences of a high BMI of $\geq 30 \mathrm{~kg} / \mathrm{m}^{2}$ for both genders and a large waist circumference of $>102 \mathrm{~cm}$ among the men and $>88 \mathrm{~cm}$ among the women increased.

Rosmond \& Björntorp (20) and Rosmond (21) have suggested that, as one of the pathophysiological mechanisms underlying the association between job strain and waist circumference, psychosocial disadvantage pressure affects the activity of the hypothalamic-pituitary-adrenal axis and, as a result, increases the cortisol level. This increase in the cortisol level then causes abdominal fat to accumulate and therefore leads to an increased waist circumference.

The measurement of saliva cortisol has frequently been used to examine the neuroendocrine excretion status in field studies. Those who perceived high chronic work overload (22) and high social stress (23) showed increased cortisol levels on awakening in the morning. The mean cortisol level of workdays was higher in a low job-control group than in a high job-control group among the men, and, among the women with a low socioeconomic status, the mean cortisol level of the workdays was higher in a high job-demand group than in a low job-demand group (24). In addition, for men, a positive association was found between the waist-tohip ratio and the cortisol response to waking (25), and, for women, the urinary cortisol level per 24 hours was increased (26).

It is well known that there is an inverse correlation between socioeconomic status and BMI among people in developed countries (27). Although people with a low socioeconomic status are expected to be under high work stress (ie, low job control), the influence of job demand-control on BMI is obscure. Job strain has not been found to be associated either with BMI in various large cross-sectional population studies among Japanese-Americans, working women, and Canadian white-collar workers (28-30), nor with weight gain in a 5-year prospective study on civil servants (31). High job demand or low job control was not associated with weight gain in the past year (32). On the other hand, according to the data collected from the 32 worksites in a cross-sectional study, the women in the high-strain group had a higher BMI than those in the other groups, but this trend was not found for the men (33). A study in France found a relationship between high job demand and overweight among women, but not among men (34). Kivimäki et al (31) pointed out the bidirectional effect of work stress on BMI as one reason for the inconsistent correlation between work stress and BMI, because work stress could not only lead to hyperphagia but also to hypophagia. The population of our study may have included some workers who lost weight due to work stress. However, no significant difference in the change in BMI or the change in waist circumference existed among the three job-strain groups for those who lost weight during the intervening period. It is possible that some of the workers who lost weight due to severe anorexia caused by work-stress-induced depression were not able to participate in the examinations because they were not working on the occasions and consequently were excluded from the participants.

Notably, in spite of focusing on the same target population, a 19-year follow-up study found work stress to be related to weight gain, while another 5-year follow-up study found no such relationship $(19,31)$. The former study noted the accumulated effect of work stress, and the observation lasted for a longer period in comparison with that of the latter study. In addition, another study pointed out that the evaluation of job strain at a single point in time possibly underestimated the association between job strain and CHD (35). Thus our previous cross-sectional study may similarly have underestimated the association between job strain and the waist-to-hip ratio.

No changes in the mean scores of job demand, job control, or worksite support were found between the first and second examinations in our study. Prior research showed stability for scores of the job content questionnaire on two occasions, before and after an average interval of 6.6 years among 2490 Europeans who remained in the same job (15). In addition, the scores of the work characteristics for the same persons did not change appreciably over a 5-year interval in Japan (36). However, the Japanese study also found that the scores were less stable when there was a position change even within the same company. Likewise, about one-third of the participants of our study showed some changes in the scores of the job content questionnaire during the 6-year period, shifting from the high group to the low group of psychosocial work characteristics and vice versa.

We categorized the persons with improved psychosocial work characteristics and those who showed deterioration in this respect together as group II, because they were likely to have experienced greater changes in other work conditions, such as workplace, shift work, and sedentary job than group I and group III did. In addition, it is difficult to know exactly when the particular change in psychosocial work characteristics started, as the effect of a change in an anthropometric measurement does not manifest itself immediately but, rather, takes time.

Adopting many factors as potential covariates may weaken the relationship between job strain and the change in BMI or the change in waist circumference. 
For instance, many people in the high-strain group had less regular exercise in association with an increased BMI and waist circumference.

Incidentally, the job-strain scores of the women in this study were higher than those of the men. Furthermore, the women rarely changed their occupations and tended to remain in a relatively low employment job. These facts may have affected the results of this follow-up study, making the relationship clearer between job strain and the change in waist circumference.

Some investigations have also shown that work stress, when evaluated in a job demand-control model, was associated with glucose metabolism, blood coagulation, and fibrinolytic function as risk factors of cardiovascular disease in Japan, as well as in other developed countries (37). Obesity (BMI $\geq 30 \mathrm{~kg} / \mathrm{m}^{2}$ ) is certainly less common in Japan than in western Europe and the United States (38). However, the proportions of overweight $\left(B M I \geq 25 \mathrm{~kg} / \mathrm{m}^{2}\right.$ ) Japanese men are $32.7 \%$ for those 40-49 years of age and $30.8 \%$ for those $50-59$ years of age. The corresponding proportions for Japanese women are $17.9 \%$ and $24.1 \%$, respectively. In addition, one in every two men and one in every five women are said to have suspected or potential metabolic syndrome (39). Therefore, the national government has begun to make a concerted effort to tackle the metabolic syndrome by making the measurement of waist circumference mandatory when people aged 40-74 years are screened in medical checkups (40).

There were several potential limitations in this study. First, we evaluated and classified psychosocial work characteristics for the same people using the job content questionnaire twice at an interval of 6 years, but we have no data on the fluctuation of the psychosocial work characteristics during this period. Similarly, although we used the scores of several confounding factors at the first examination, we did not record their subsequent changes. In addition, as about $25 \%$ of the men and about $20 \%$ of the women of all of the participants either retired, were transferred, did not fill out the questionnaire completely, or refused to participate in this examination, they were excluded from the follow-up survey. This exclusion may have conceivably affected the results, although a large population of both genders was available for continued follow-up. Second, the waist circumference was lower for group III in the first examination. This initial low score may possibly have contributed to the increase in waist circumference in the second examination. However, especially for the women, the difference in the change in waist circumference among the three job-strain groups was larger than the difference affected by the initial potential bias. Third, we did not make a dietary survey with respect to weight gain. However, a large-scale survey of 25000 Japanese by Kawakami et al (41) did not reveal any evident connection between job strain and total energy intake, even after adjustment for age, educational background, and occupation. Fourth, since the participants of our study were all from a single company, whether our results can be generalized or not will have to be determined in further studies.

In conclusion, we examined psychosocial work characteristic twice for 2200 men and 1371 women with an interval of 6 years between the examinations. We admit that there was a bidirectional influence of work stress on BMI and waist circumference, and yet the results of our study showed that high job strain increased the change in waist circumference even when several potential confounding factors were taken into consideration. This result supports the finding of Brunner et al (19), who reported that chronic work stress may contribute to abdominal obesity. Hence it is important that we take measures to reduce the chronic work stress of workers in terms of preventing atherosclerotic and other diseases triggered by the metabolic syndrome.

\section{Acknowledgments}

A part of this study was supported by a grant-in-aid for scientific research (C:13670395:2001-2003) from the Japanese Ministry of Education, Culture, Science and Technology.

\section{References}

1. Schnall PL, Landsbergis PA, Baker D. Job strain and cardiovascular disease. Annu Rev Public Health. 1994;15:381-411.

2. Belkic K, Landsbergis PA, Schnall PL, Baker D. Is job strain a major source of cardiovascular disease risk? [review]. Scand J Work Environ Health. 2004;30(2):85-128.

3. Schnall PL, Pieper C, Schwartz JE, Karasek RA, Schlussel Y, Devereux RB, et al. The relationship between "job strain," workplace diastolic blood pressure, and left ventricular mass index: results of a case-control study. JAMA. 1990;263:192935 .

4. Light KC, Turner R, Hinderliter AL. Job strain and ambulatory work blood pressure in healthy young men and women. Hypertension. 1992;20:214-8.

5. Von Känel R, Mills PJ, Fainman C, Dimsdale JE. Effects of psychological stress and psychiatric disorders on blood coagulation and fibrinolysis: a biobehavioral pathway to coronary artery disease? Psychosom Med. 2001;63:531-44.

6. Expert Panel on Detection, Evaluation, and Treatment of High Blood Cholesterol in Adults: executive summary of the third report of the National Cholesterol Education Program (NCEP) Expert Panel on Detection, Evaluation, and Treatment of High Blood Cholesterol in Adults (adult treatment panel III). JAMA. 2001;285:2486-97.

7. Brunner EJ, Marmot MG, Nanchahal K, Shipley MJ, Stansfeld SA, Juneja M, et al. Social inequality in coronary risk: central 
obesity and the metabolic syndrome: evidence from the Whitehall II study. Diabetologia. 1997;40:1341-9.

8. Chandola T, Brunner, Marmot M. Chronic stress at work and the metabolic syndrome: prospective study. BMJ. 2006;332:521-5.

9. Rosmond R, Lapidus L, Björntorp P. The influence of occupational and social factors on obesity and body fat distribution in middle-aged men. Int J Obes. 1996;20:599-607.

10. Rosmond R, Björntorp P. Psychosocial and socio-economic factors in women and their relationship to obesity and regional body fat distribution. Int J Obes. 1999;23:138-45.

11. Ishizaki M, Morikawa Y, Nakagawa H, Honda R, Kawakami $\mathrm{N}$, Haratani T, et al. The influence of work characteristics on body mass index and waist to hip ratio in Japanese employees. Ind Health. 2004;42:41-9.

12. Wainwright D, Calnan M. Work stress. Buckingham, Philadelphia: Open University Press; 2002. p 124-63.

13. Kawakami N, Kobayashi F, Araki S, Haratani T, Furui H. Assessment of job stress dimensions based on the job demands-control model of employees of telecommunication and electric power companies in Japan: reliability and validity of the Japanese version of job content questionnaire. Int J Behav Med. 1995;2:358-75.

14. Kawakami N, Haratani T, Kobayashi F, Ishizaki M, Hayashi T, Fujita O, et al. Occupational class and exposure to job stressors among employed men and women in Japan. J Epidemiol. 2004; 14:204-11.

15. Clays E, De Bacquer D, Leynen F, Kornitzer M, Kittel F, De Backer G. Long-term changes in the perception of job characteristics: results from the Belstress II-study. J Occup Health. 2006;48:339-46.

16. Georges E, Wear ML, Mueller WH. Body fat distribution and job stress in Mexican-American men of the Hispanic health and nutrition examination survey. Am J Hum Biol. 1992;4:657-67.

17. Jönsson D, Rosengren A, Dotevall A, Lappas G, Wilhelmsen L. Job control, job demands and social support at work in relation to cardiovascular risk factors in MONICA 1995, Göteborg. J Cardiovasc Risk. 1999;6:379-85.

18. Overgaard D, Gyntelberg F, Heitmann BL. Psychological workload and body weight: is there an association?: a review of the literature. Occup Med. 2004;54:35-41.

19. Brunner EJ, Chandola T, Marmot MG. Prospective effect of job strain on general and central obesity in the Whitehall II study. Am J Epidemiol. 2007;165:828-37.

20. Rosmond R, Björntorp P. Occupational status, cortisol secretory pattern, and visceral obesity in middle-aged men. Obes Res. 2000;8:445-50.

21. Rosmond R. Aetiology of obesity: a striving after wind?. Obes Rev. 2004;5:177-81.

22. Schulz P, Kirschbaum C, Prübner J, Hellhammer D. Increased free cortisol secretion after awakening in chronically stressed individuals due to work overload. Stress Med. 1998;14:91-7.

23. Wüst S, Federenko I, Hellhammer DH, Kirschbaum C. Genetic factors, perceived chronic stress, and the free cortisol response to awakening. Psychoneuroendocrinology 2000;25:707-20.

24. Kunz-Ebrecht SR, Kirschbaum C, Steptoe A. Work stress, socioeconomic status and neuroendocrine activation over the working day. Soc Sci Med. 2004;58:1523-30.

25. Wallerius S, Rosmond R, Ljung T, Holm G, Björntorp P.
Rise in morning saliva cortisol is associated with abdominal obesity in men: a preliminary report. J Endocrinol Invest. 2003;26:616-9.

26. Mårin P, Darin N, Amemiya T, Andersson B, Jern S, Björntorp P. Cortisol secretion in relation to body fat distribution in obese premenopausal women. Metabolism. 1992;41:882-6.

27. Brunner E. The social and biological basis of cardiovascular disease in office workers. In: Blane D, Brunner E, Wilkinson $\mathrm{R}$, editors. Health and social organization. London and New York: Routledge; 1996. p 272-99.

28. Reed DM, Lacroix AZ, Karasek RA, Miller D, Maclean CA. Occupational strain and the incidence of coronary heart disease. Am J Epidemiol. 1989;129:495-502.

29. Amick BC 3rd, Kawachi I, Coakley EH, Lerner D, Levine S, Colditz GA. Relationship of job strain and iso-strain to health status in a cohort of women in the United States. Scand J Work Environ Health. 1998;24(1):54-61.

30. Brisson C, Larocque B, Moisan J, Vézina M, Dagenais GR. Psychosocial factors at work, smoking, sedentary behavior, and body mass index: a prevalence study among 6995 white collar workers. J Occup Environ Med. 2000;42:40-6.

31. Kivimäki M, Head J, Ferrie JE, Shipley MJ, Brunner E, Vahtera $\mathrm{J}$, et al. Work stress, weight gain and weight loss: evidence for bidirectional effects of job strain on body mass index in the Whitehall II study. Int J Obes. 2006;30:982-7.

32. Lallukka T, Laaksonen M, Martikainen P, Sarlio-Lähteenkorva S, Lahelma E. Psychosocial working conditions and weight gain among employees. Int J Obes. 2005;29:909-15.

33. Hellerstedt WL, Jeffery RW. The association of job strain and health behaviours in men and women. Int $\mathrm{J}$ Epidemiol. 1997;26:575-83.

34. Niedhammer I, Goldberg M, Leclerc A, David S, Bugel I, Landre MF. Psychosocial work environment and cardiovascular risk factors in an occupational cohort in France. J Epidemiol Community Health. 1998;52:93-100.

35. Kivimäki M, Head J, Ferrie JE, Brunner E, Marmot MG, Vahtera $\mathrm{J}$, et al. Why is evidence on job strain and coronary heart disease mixed?: an illustration of measurement challenges in the Whitehall II study. Psychosom Med. 2006;68:398-401.

36. Kayaba K, Tsutsumi A, Gotoh T, Ishikawa S, Miura Y. Fiveyear stability of job characteristics scale scores among a Japanese working population. J Epidemiol. 2005;15:228-34.

37. Kawakami N, Haratani T. Epidemiology of job stress and health in Japan: review of current evidence and future direction. Ind Health. 1999;37:174-86.

38. Organization for Economic Co-operation and Development (OECD). OECD health data 2001: comparative analysis of 30 OECD countries. Paris: OECD; 2001.

39. Ministry of Health, Labour and Welfare of Japan. The national health and nutrition survey in Japan, 2004 [in Japanese]. Tokyo: Daiichi; 2006.

40. Health and Welfare Statistics Association. [in Japanese] J Health Welfare Stat. 2007;54(9):92.

41. Kawakami N, Tsutsumi A, Haratani T, Kobayashi F, Ishizaki M, Hayashi T, et al. Job strain, worksite support, and nutrient intake among employed Japanese men and women. J Epidemiol. 2006;16:79-89.

Received for publication: 19 November 2007 